\title{
Morfologia urbana como instrumento projetual
}

\author{
Urban morphology as design tool
}

Renato Leão Rego[a] (D), Karin Schwabe Meneguetti[a] (D), Gislaine Elizete Beloto[a] (D)

[a] Universidade Estadual de Maringá (UEM), Departamento de Arquitetura e Urbanismo, Maringá, PR, Brasil

Como citar: Rego, R. L., Meneguetti, K. S., \& Beloto, G. E. (2020). Morfologia urbana como instrumento projetual. urbe. Revista Brasileira de Gestão Urbana, 12, e20190266. https://doi.org/10.1590/2175-3369.012.e20190266

\section{Resumo}

Este artigo trata da adaptação de conceitos de morfologia originalmente desenvolvidos no contexto de formas urbanas antigas para a realidade de cidades do novo mundo, particularmente as cidades planejadas fundadas no Brasil do século XX. 0 texto se refere a urban fringe belts, morphological region, morphological frame, tipo edilício e processo tipológico, e apresenta uma experiência prática de aplicação desses conceitos no exercício projetual de uma vizinhança a ser implantada em uma forma urbana consolidada. 0 conceito de urban fringe belts foi correlacionado à ecologia da paisagem, de modo a explorar seu potencial ecológico e, ciente da inexorabilidade desse elemento morfológico na dinâmica urbana, a sugerir sua abordagem integrada no planejamento da cidade.

Palavras-chave: Cidades novas. Projeto urbano. Conceitos morfológicos. Escola inglesa. Escola italiana.

\section{Abstract}

This paper accounts for the adaptation of morphological concepts originally developed in the context of old urban forms to the reality of New World towns, particularly the planned new towns founded in twentiethcentury Brazil. The study refers to urban fringe belts, morphological region, morphological frame, building type and typological process, and presents a practical experience, in which these concepts were applied in a planning exercise aiming to create a new neighbourhood in a consolidated urban setting. The urban fringe belt concept was correlated with Landscape Ecology in order to explore its ecological potential and, aware of its inexorability in the urban dynamics, suggest its integrated approach in the city planning.

Keywords: New towns. Urban design. Morphological concepts. English school. Italian school.

\section{Introdução}

Há algum tempo, Costa \& Teixeira (2014) concluíram que poucos estudos no Brasil empregavam conceitos de morfologia urbana e desenvolviam análises morfológicas de modo satisfatório. 0 campo disciplinar da morfologia urbana mostrou avanços significativos desde então, com produções 
conceitualmente mais consistentes e com resultados mais efetivos, pois publicações em língua portuguesa trataram de disseminar bases teórico-conceituais, principalmente aquelas decorrentes das escolas inglesa e italiana de morfologia, e orientar sua aplicação em estudos brasileiros (Costa \& Netto, 2015; Oliveira, 2016a, 2016b, 2018; Oliveira \& Monteiro, 2015), como fizeram Rego \& Meneguetti (2011). Há que se acrescentar também o papel instrutivo dos Seminários Internacionais de Forma Urbana (ISUF) e, sobretudo, dos encontros da Rede Lusófona de Morfologia Urbana (PNUM), realizados anualmente desde 2011 em Portugal e no Brasil.

A difusão sistematizada de conceitos morfológicos tem necessariamente que passar pela "tradução" e eventual adaptação desses conceitos às particularidades locais. Originalmente desenvolvidos a partir de e para - formas urbanas seculares, esses conceitos provavelmente sofram ajustes quando aplicados em cidades novas. Esse é o caso, por exemplo, das faixas de hiato urbano - urban fringe belts -, um conceito orginalmente desenvolvido a partir da evolução espaço-temporal de tecidos urbanos medievais e transposto à realidade das cidades brasileiras e que assim adquiriu novas nuances (Meneguetti \& Costa, 2015; Pereira et al., 2011).

Nesse sentido, na sua primeira parte, este artigo tratará de apresentar conceitos fundamentais da morfologia urbana aplicados ao contexto brasileiro, a partir da compilação de trabalhos publicados nos últimos anos. 0 conceito de urban fringe belts, citado ainda há pouco, será aproximado da noção de green wedges (Oliveira, 2017) e, por seu potencial ecológico (Hopkins, 2003; Whitehand, 2019), associado à abordagem da ecologia da paisagem. 0 artigo tratará ainda de morphological frame e de morphological region, conceitos conzenianos que muito se aproximam da noção de unidades de paisagem, já bastante desenvolvida no Brasil por meio dos trabalhos da rede Quapá-SEL (Macedo et al., 2018). Na segunda parte, o artigo discutirá o crescimento urbano e tipo e processo tipológico em um contexto brasileiro. Tendo em mente que estudos analíticos e descritivos são etapas preliminares fundamentais de abordagens prescritivas, a terceira parte do artigo relatará a experiência projetual levada a cabo na Oficina de Morfologia Urbana realizada na Universidade Estadual de Maringá em 2018. Intitulado de Expandindo Maringá: morfologia urbana e preceitos ecológicos em novos parcelamentos - Oficina PNUM 2018, esse workshop teve como objetivo a conexão entre a base teórico-analítica da morfologia com seu potencial prospectivo. 0 relato dessa experiência pode desencadear outras iniciativas acadêmicas e novas práticas didáticas e profissionais. Assim, é trazido para a discussão presente aquilo que é proeminente na disciplina de urbanismo - seu aspecto propositivo como contribuição para qualidade ambiental e urbana - em conjunto com a morfologia urbana.

\section{Lições da escola inglesa para o estudo de cidades novas}

Estudos de cidades planejadas ex novo podem contribuir para o reconhecimento da sua gênese ao considerar a forma urbana como manifestação física de um contexto cultural específico. A morfologia urbana pode responder a questões como o aparecimento das diferentes formas urbanas encontradas ou, ainda, o porquê de certas formas persistirem ou se disseminarem (Kropf, 2011, p. 159). Apoiados em escrituras, contratos de compra e venda, relatos biográficos e de viagens, registros fotográficos e, com sorte, em mapas originais remanescentes, por vezes esparsos, os estudos morfológicos ajudam a inferir e narrar a conformação das cidades que, embora recente, é escassa de documentação. Nesse sentido, morfologia e história da cidade e do urbanismo se amparam mutuamente. Isso é o que se pode perceber em estudos recentes de cidades inseridas em processos de colonização dirigida, seja ela de iniciativa privada, seja governamental (Rego \& Meneguetti, 2008, 2010; Rego, 2015, 2017a). A morfologia tem explicado a gênese do traçado planejado dessas cidades, assim como sua posição geográfica e sua relação no âmbito regional, interessando-se também pela sua inserção no território e o modo como um conjunto de formas urbanas constitui a paisagem regional e interage com as estruturas em tal escala.

Nesse aspecto, a escola inglesa de morfologia, com seu foco na abordagem cognitiva, tem sido particularmente seminal, em especial a divisão tripartite estabelecida por Conzen (Conzen, 2004; 
Whitehand, 2001; Costa \& Netto, 2015): o traçado ou a planta da cidade, que consiste de ruas, quadras e lotes; depois, o conjunto edificado e os padrões de distribuição, que conformam o tecido edificado; e, por fim, o uso do solo urbano. No caso do estudo de cidades planejadas ex novo, a análise deve remontar ao projeto inicial da nova forma urbana transposto ao sítio, já que o conjunto edificado foi sendo paulatinamente implementado. Ainda assim, a observação de forma, tamanho e disposição de quadras, consideradas em relação à posição das edificações públicas, institucionais e comerciais, conjugadas com a presença e a configuração dos espaços livres, revela as características particulares da forma urbana. Com a evolução do traçado implementado, a observação do tecido edificado completa a análise conzeniana, tridimensional, e revela se as intenções projetuais iniciais se confirmaram na paisagem edificada e arremata a explicação da fisionomia da cidade.

Conzen (2004) registrou que o uso do solo urbano se altera mais rápido e frequentemente, enquanto o conjunto edificado e o plano da cidade se mantêm inalterados por mais tempo. No caso de cidades planejadas, até mesmo o traçado urbano sofre transformações, as quais, por vezes, significam adaptação ou rejeição do modo de vida urbana imposto pela configuração da nova cidade, na maioria das vezes idealizada à distância para uma população desconhecida. Em geral implementando ideias urbanísticas inovadoras, esses traçados acabaram alterados porque os valores embutidos nos projetos dessas novas cidades, por meio de configurações pouco tradicionais ou convencionais para a quadra, o lote, a rua e a habitação, não fizeram sentido para a população que veio a ocupar tais espaços. Ao analisar a conformação da unidade de vizinhança em Goiânia, Brasília e Rurópolis e relatar sua construção, sua ocupação e seu uso, Rego (2017b) reconheceu transformações na ideia original resultantes da incompreensão, da discordância ou da rejeição por parte da população a certo modo de vida preestabelecido, apontando a utopia do urbanismo moderno e o problema das formas urbanas ideais; o estudo morfológico, ao reconhecer a forma inicial da cidade e suas recorrentes transformações, fez notar que a modificação, a deformação e mesmo a extinção das unidades de vizinhança resultaram de inadequação física e incompatibilidade sociocultural.

Conzen (2004, p. 251) também definiu como região morfológica uma área homogênea da paisagem urbana, caracterizada por desenvolvimento parecido, evidenciado na semelhança do traçado, do padrão das edificações e da ocupação e no uso do solo em conjunto com as particularidades físico-ambientais do sítio. No caso de cidades em que o sítio apresenta uniformidade considerável, com poucas variações em suas características físicas, em especial na declividade do terreno, esse conceito tem rebatimento na noção de unidades de paisagem, explorada nos estudos dos sistemas de espaços livres nas cidades brasileiras (Meneguetti et al., 2012). A identificação de unidades de paisagem permite compreender práticas recorrentes de urbanização que, em meio às condicionantes físicas e à legislação vigente, não deixam de servir como modelo a ser replicado. A compreensão da "preferência" latente em uma certa unidade de paisagem - uma questão de fundo sociocultural - é um potente instrumento para o projeto de novas vizinhanças, já que elas tendem a se concretizar dentro de uma mesma "moldura morfológica" (Conzen, 2004, p. 251) e, com isso, podem evitar a rejeição por inadequação física e incompatibilidade sociocultural (Figura 1). A moldura morfológica na qual se instalará uma nova vizinhança é, em tradução livre,

[...] a característica de um traçado antecedente, de um perfil topográfico ou de um conjunto de configurações exercendo influência morfológica sobre projetos subsequentes e frequentemente passando adiante seus componentes como formas herdadas (Conzen, 2004, p. 251) ${ }^{1}$.

\footnotetext{
1 "An antecedent plan feature, topographical outline, or set of outlines exerting a morphological influence on subsequent more or less conformable plan development, and often passing its features on as inherited outlines, (Conzen, 1969, p. 127)”. Cf. ISUF (2019).
} 


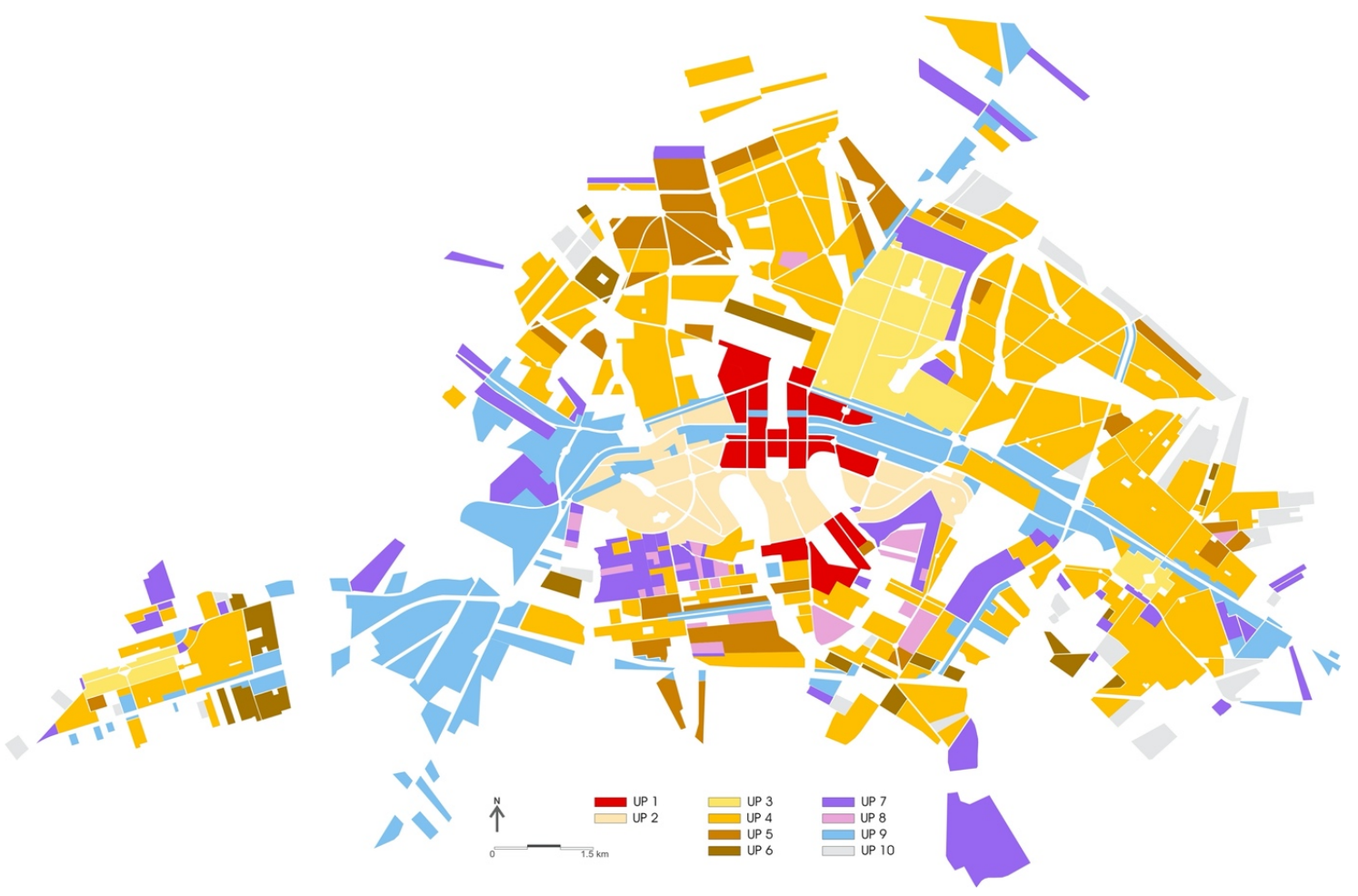

Figura 1 - Unidades de paisagem na mancha urbana de Maringá. Fonte: Meneguetti et al. (2012).

Voltando ao aspecto cognitivo da morfologia, os estudos morfológicos reconheceram que a forma urbana está em constante evolução e que seu crescimento acompanha e materializa ciclos de crescimento e retração da economia. 0 conceito conzeniano de urban fringe belts, discutido por Whitehand (2001), reconheceu, no contexto de cidades europeias,

[...] uma zona em formato de cinturão originária da expansão temporária, estacionária ou muito lenta de uma cidade, e composta de unidades de usos mistos característicos, que originalmente buscam localização periférica. [...] Em cidades com uma longa história, este resultado geográfico emergindo gradualmente dessas dinâmicas é frequentemente um sistema de quase-anéis concêntricos sucessivos, mais ou menos separados por outros, usualmente tecidos residenciais. (Conzen, 1969, p. 125) 2 .

O conceito de fringe belts se mostrou pertinente e válido para o caso de cidades novas no contexto brasileiro. A "tradução" e a adaptação desse conceito, levadas a cabo por Pereira et al. (2011), confirmaram que a faixa de hiato urbano é uma textura distinta no tecido urbano e que sua constituição e identificação têm uma relação estreita com a vida urbana e o entendimento da sua dinâmica socioeconômica. Entretanto, no estudo realizado inicialmente na cidade de Maringá (Pereira et al., 2011), verificou-se que as faixas de hiato urbano não conformavam cinturões como nos estudos das cidades de origem medieval. 0 que se identificou no estudo de caso brasileiro (Figura 2) foi a tendência de formação de arcos ou faixas de hiato que refletiam a história econômica-cultural da cidade e o crescimento urbano, em certa medida, planejado. Tais faixas foram determinadas por lotes de grandes dimensões e usos variados, implicando baixa densidade construtiva e presença de grandes equipamentos institucionais. A Figura 2 demonstra o aparecimento das faixas de hiato urbano em localização limítrofe entre a área urbana e a rural, permitindo distinguir as épocas de formação dessas faixas ao longo da vida da cidade. Embora algumas faixas de hiato urbano sejam transformadas em áreas de apropriação e uso público, como áreas verdes ou de edifícios institucionais, muitas delas permanecem com sua característica original, de ser tão urbanas quanto rural (Whitehand, 2001).

\footnotetext{
${ }^{2}$ Para mais detalhes, cf. ISUF (2019).
} 


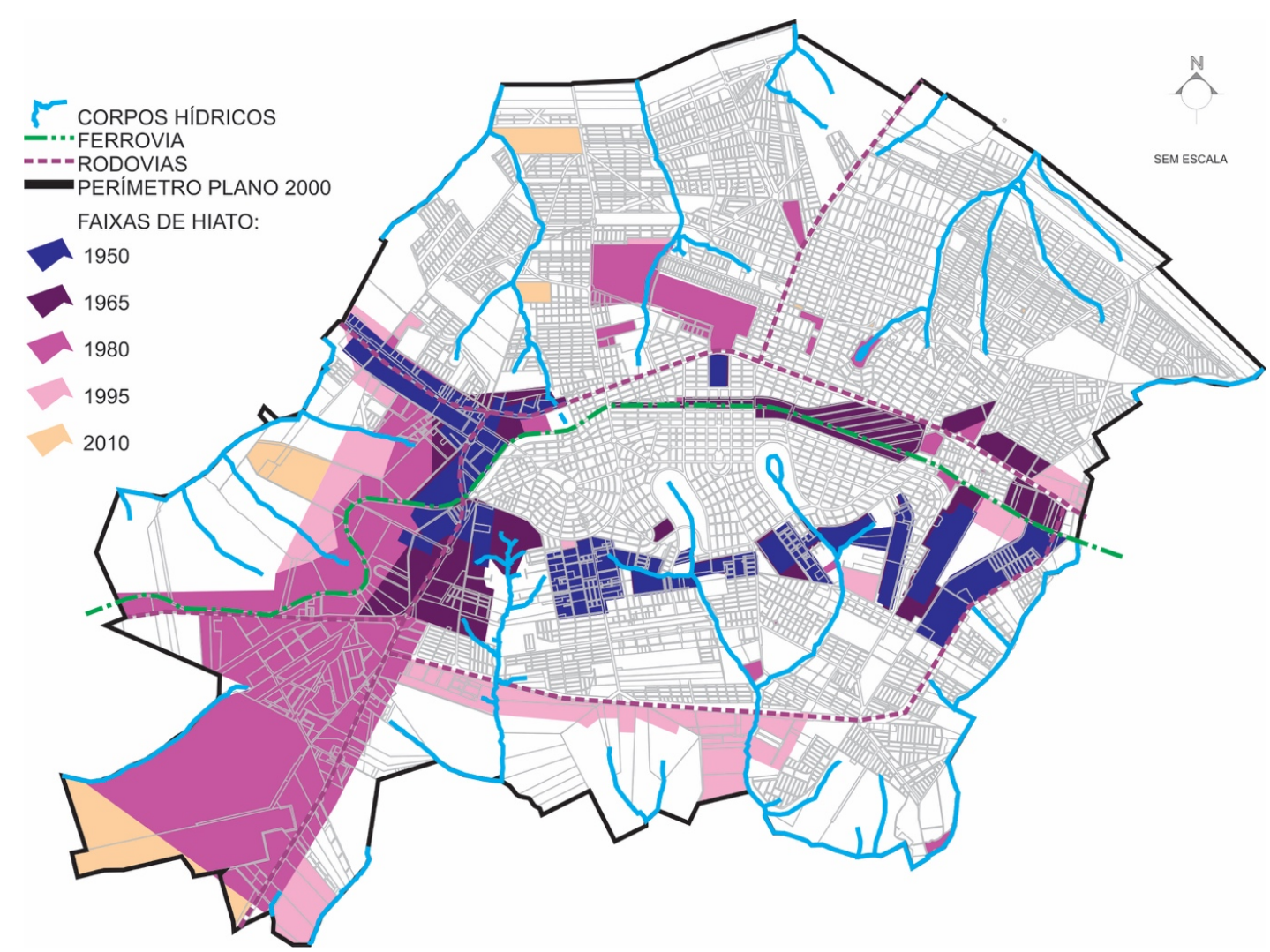

Figura 2 - Evolução das faixas de hiato urbano em Maringá. Fonte: Meneguetti (2015).

Como explicitado em Meneguetti (2015), as faixas de hiato urbano de Maringá obedecem aos mesmos princípios de formação e transformação expostos na literatura. De acordo com a Figura 2, em 1950 veem-se os hiatos em processo de formação, e a faixa de hiato desse período corresponde aos usos estrategicamente implantados além dos limites urbanos (aeroporto, cemitério, horto florestal, chácaras de produção hortifrutigranjeira, áreas industriais) ou internamente à área urbana, mas justaposta aos seus limites, como a área industrial e as áreas de comércio atacadista ligadas à linha férrea e ao pátio de manobras. No período subsequente, há algumas transformações e, principalmente, a formação de novos hiatos, com a criação de um clube social, do parque de exposições e de novas áreas industriais. No período de 1966-1980, a formação de faixas de hiato corresponde ao estabelecimento do campus da Universidade Estadual de Maringá, de outro clube social, de um novo parque, de áreas institucionais ao norte da cidade e da estação de tratamento de esgoto ao sul. 0 período de 1981-1995 revela poucos acréscimos e aponta perdas por processo de alienação, principalmente na área lindeira à linha férrea. 0 último período pesquisado - 1996-2010 - também se caracteriza por poucas modificações nas faixas de hiato, porém de modo mais variado que no período anterior. Pela primeira vez aparece o processo de transferência, relativo à construção de um novo aeroporto e à liberação da área do anterior para uso residencial, em contraste com o acréscimo de áreas junto à zona industrial.

No refinamento desses estudos (Meneguetti \& Costa, 2015; Meneguetti, 2015), foi observado que a temporalidade na transformação da cidade brasileira e, consequentemente, das suas faixas de hiato urbano se restringe a um pequeno intervalo - de poucas décadas -, diferentemente do que se notou nos estudos internacionais reconhecidos. Contudo, mais importante que essa particularidade do estudo de caso maringaense é o fato de o conceito ter se mostrado válido e aplicável a uma cidade nova e planejada, especialmente no Brasil. Esse trabalho entendeu que o reconhecimento da criação de faixas de hiato urbano pode favorecer o sistema de espaços livres da cidade, sobretudo se a sua lógica for incorporada ao planejamento urbano. Nesse sentido, os hiatos urbanos merecem maior consideração do que têm recebido no planejamento e projeto urbanos e um tratamento integrado (Whitehand, 2019). Como apontado por Hopkins (2003), as faixas de hiato incluem um componente biológico significativo, o qual, 
potencializado pela baixa intensidade edilícia e maior cobertura vegetal observada nas faixas de hiato urbano, pode conectá-las aos sistemas ecológicos que operam em diferentes escalas espaciais, na coexistência entre a sociedade urbana e a vida selvagem (Hopkins, 2003).

A interação entre a natureza e a cidade também pode ser valorizada com o reconhecimento de green wedges na forma urbana. O conceito de green wedges, ou cunhas verdes, é derivado de modelos urbanísticos apresentados no início do século XX como um contraponto ao green belt e ao modelo de crescimento urbano limitado e concêntrico (Oliveira, 2017). As cunhas verdes estão naturalmente presentes em cidades que se desenvolveram sobre divisores de água e cujas nascentes dos corpos hídricos se encontram encravadas no meio do tecido urbano. Dessa forma, essas cidades têm grande probabilidade de que as estruturas naturais formadas por córregos e matas ciliares venham a se tornar áreas verdes de penetração no tecido urbano.

\section{Lições da escola italiana}

A partir do viés analítico e prescritivo da escola italiana de morfologia, o crescimento da cidade pode ser compreendido pela dinâmica reconhecida em seus elementos estruturais (Panerai, 2006; Castex \& Panerai, 1970). Desse modo, polo e linha de crescimento, barreiras e limites ao crescimento condicionam e conduzem as transformações no território. A observação da forma em sua evolução urbana revela a dinâmica desses elementos e pode respaldar decisões de planejamento.

0 entendimento das diferentes formas do crescimento urbano permitiu compreender a transformação na configuração dos núcleos comerciais e de serviços originalmente implantados em Maringá. A partir da conjugação dos conceitos "crescimento unidirecional" e "linhas de crescimento" ou ainda de "crescimento multidirecional" e "polo de crescimento", tem sido possível compreender as áreas de articulação dos vetores de expansão urbana.

Por meio da análise estrutural espaço-tempo e do uso do solo, percebeu-se que o comércio na cidade de Maringá não se ateve aos centros secundários originalmente delineados e alongou-se pelas suas imediações, e o remoto shopping center regional, que, em princípio, estava no limite da forma urbana, acabou criando uma nova centralidade, atraindo o crescimento urbano para o seu entorno imediato (Braga \& Rego, 2019; Beloto \& Coimbra, 2019). No caso dos centros secundários, que deveriam concentrar o comércio no bairro residencial, houve um crescimento linear correspondente à importância das vias como linhas de crescimento e como ordenamento do tecido urbano, desconfigurando os centros comerciais e reconfigurando-os em eixos de comércio. Por sua vez, o shopping center e os centros universitários vêm demonstrando ser equipamentos urbanos potencializadores de novas centralidades, provocando um crescimento multidirecional (Figura 3). Assim, está em andamento a constituição de uma nova estrutura da forma urbana, mais uma vez polinucleada, entretanto com centros de abrangências muito além da escala do bairro proposta no projeto original. 


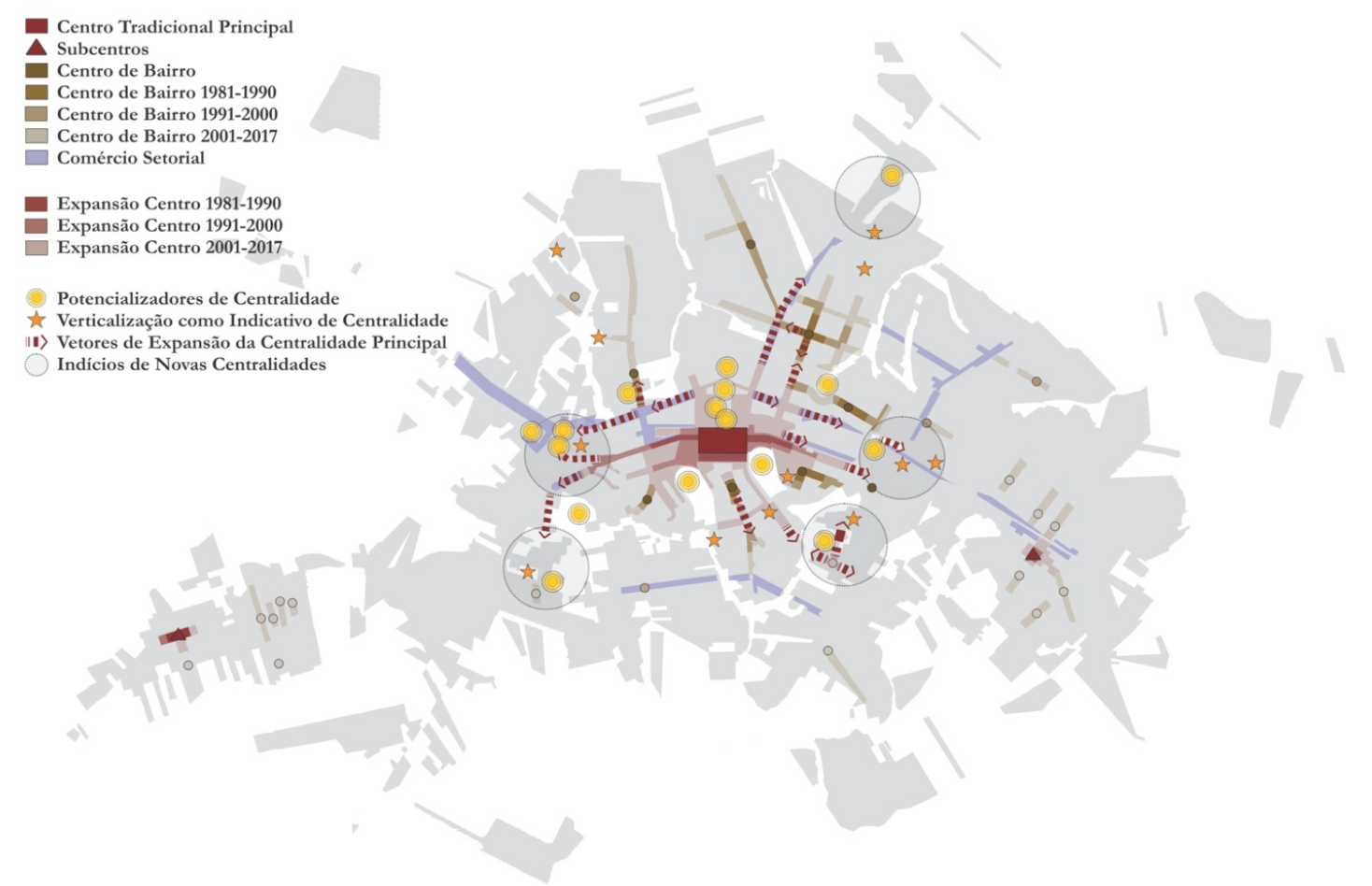

Figura 3 - Deslocamento das centralidades em Maringá. Fonte: Beloto \& Coimbra (2019).

Naquilo que concerne à expansão territorial, a cidade tem sido construída por meio da transformação da parcela rural em urbana. A matriz que dá suporte à expansão das cidades em todo o norte do Estado do Paraná deriva do parcelamento prévio em pequenas propriedades rurais, cuja forma regular, tendendo ao retângulo, parte sempre das estradas vicinais que se localizam sobre os divisores de águas e prosseguem até o talvegue mais próximo. Certamente tal disposição foi possibilitada pela configuração dendrítica da rede hídrica da região. A regularidade na forma dos lotes rurais e a sua dimensão, ambas aliadas à rentabilidade na produção do solo urbano, têm gerado um traçado urbano regular, porém desconexo, dadas as distintas iniciativas de parcelamento. 0 resultado apresenta quadras retangulares alongadas que abrigam lotes de dimensões mínimas para futuras subdivisão.

Os trabalhos relacionados à escola italiana de morfologia centrados no conceito de tipo edilício são adequados para o reconhecimento de permanências e mudanças nas características dessa paisagem urbana. Desse modo, esse conceito pode reforçar a existência de uma moldura morfológica e amparar o processo projetual de novas áreas urbanas. Mesmo na paisagem menos uniforme e mais desornada das cidades brasileiras, é possível reconhecer tipos edilícios e seu enraizamento sociocultural.

A expansão de cidades novas planejadas na zona de colonização norte-paranaense, notadamente aquela que compõe a mancha urbana de Maringá, revela um modo bastante comum de se "fazer" cidade. Neste estudo de caso, as unidades de paisagem mais periféricas apresentam características morfológicas similares, e nelas é possível notar a persistência de determinado tipo edilício. Uma certa forma de construir - de divisa a divisa, utilizando os muros laterais como paredes das casas, com duas águas de telhado e a cumeeira paralela à testada do lote (Figura 4) - iniciou-se pelas camadas mais baixas da pirâmide social, que buscavam economia na construção com o aproveitamento dos muros de divisa. Valendo desse tipo edilício e atendendo à necessidade de diminuir o custo da terra, o lote residencial convencional foi subdividido em dois, perpendicularmente ao alinhamento predial, e passou a acomodar duas unidades habitacionais com 6 metros de frente cada uma delas (Figura 5), mesmo em bairros de classe média. Esse modo de fazer a habitação passou a representar, em certa medida, a edificação "moderna", em contraponto à pequena casa solta das divisas do lote, frequentemente de madeira, que caracterizou o início da ocupação urbana, e com isso foi repetido como diretriz construtiva adotada em parte por economia, em parte por motivação cultural. 


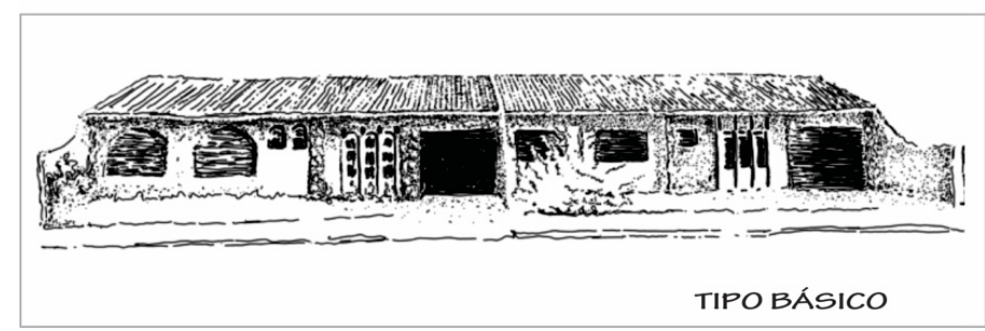

Figura 4 - Tipo edilício básico em sequência. Fonte: Meneguetti et al. (2017).

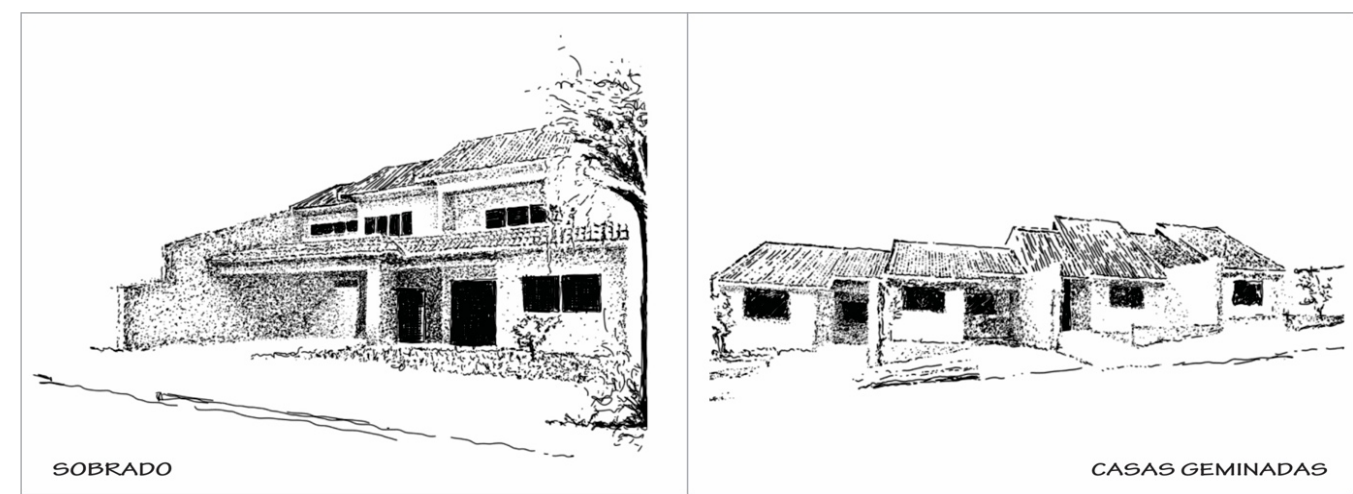

Figura 5 - Diversificação do tipo edilício. Fonte: Meneguetti et al. (2017).

O tecido urbano de áreas residenciais totalmente ocupadas sofreu alterações com a substituição das residências isoladas no lote por unidades geminadas, que permearam classes de renda distintas. Esse tipo edilício, uma solução formal coletivamente assimilada e, portanto, parte da paisagem urbana existente, passou então a ser adotado pelo loteador que empreendia a expansão da cidade como parâmetro métrico de novas urbanizações. Consequentemente, houve uma pressão social para que esse parâmetro métrico fosse admitido como parâmetro legal de ocupação e parcelamento do solo urbano, condicionando a forma dos novos loteamentos. Portanto, e de acordo com Gauthier (2005), notou-se que o tipo se consolidou a partir de maquinações de determinantes externos e internos, ou seja, uma relação complexa entre um modelo cultural e demandas sociais externas.

Assim, o processo tipológico demonstra que uma mesma solução arquitetônica serviu como resposta aos mais variados condicionantes locacionais ou econômicos, correspondendo a uma variação sincrônica (Figura 6), provocada pela inserção de um tipo básico em um tecido urbano já consolidado e uma variação diatópica, identificada pela coexistência de interpretações diferentes do mesmo tipo básico (Costa \& Netto, 2015, p. 159). 


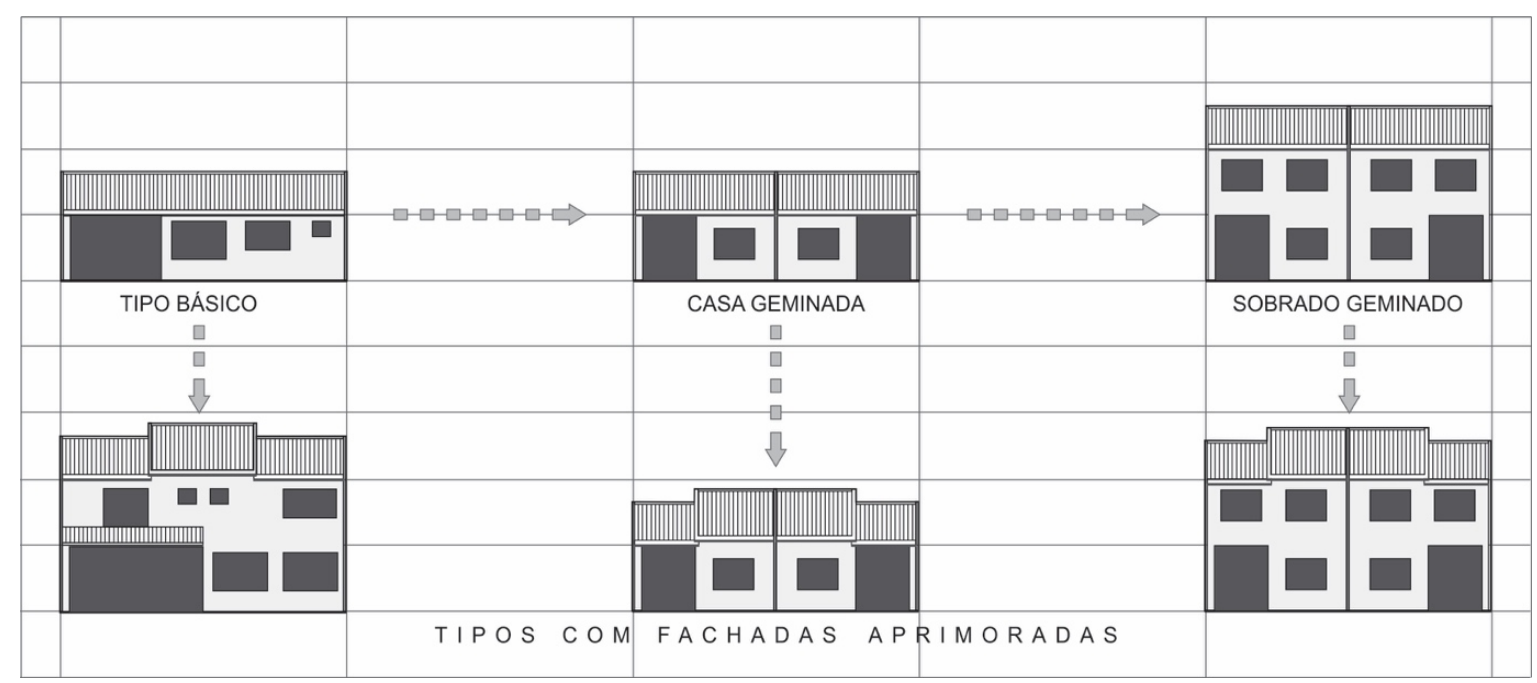

Figura 6 - Processo tipológico. Fonte: Meneguetti, Beloto \& Rego (2017).

\section{O estudo da forma urbana e a prática projetual}

Nota-se no Brasil uma noção ainda potente de que projetar significa conceber algo inovador e distinto da realidade que circunda a todos - uma noção decorrente da forte hegemonia do pensamento modernista na formação profissional. Uma visão menos idealizada e mais condescendente com as realidades locais e com as particularidades do cidadão comum - e, portanto, pós-modernista - é parte do corpo teórico da morfologia, já que ela está interessada na prática comum, tradicional, e não na exceção. Reconhecer o contexto para inserir nele algo que não lhe é estranho é uma prática que merece reforço conceitual, pois, muitas vezes, ela acontece, embora sem o respaldo teórico conveniente ou os preceitos que lhe embasam. Desse modo, a Oficina de Morfologia Urbana realizada em 2018 na Universidade Estadual de Maringá (UEM, 2019) tratou de disseminar conceitos morfológicos fundamentais e desenvolver uma prática projetual alicerçada nesses conceitos.

Diante do objetivo principal desse workshop, a porção sul da cidade Maringá foi escolhida para o exercício prático, pois esse é um setor da cidade cuja expansão tem gerado fragmentos na forma da mancha urbana. Novos loteamentos têm expandido e fragmentado a porção sul da mancha urbana resultante da proximidade entre as cidades de Maringá, Sarandi e Paiçandu. Isoladas, essas novas áreas residenciais têm apresentado pouca qualidade espacial, com um traçado regular, especulativo, com baixa aderência ao sítio e poucas considerações ambientais. Reverter esse quadro é um grande desafio profissional e intervir nessa realidade é certamente uma rica experiência projetual, na medida em que contribuições teóricas podem ser postas em prática e soluções alternativas de desenho urbano podem ser imaginadas. Portanto, o objetivo desse workshop foi propor conexões entre os loteamentos recentemente abertos, novas vizinhanças e espaços livres remanescentes. Ao se tratar de uma área de expansão circundada por unidades de paisagem diversas, e cujo limite se dá por um curso d'água com suas bordas recobertas por mata ciliar, aspectos culturais e naturais tiveram sua importância destacada (Figura 7). 


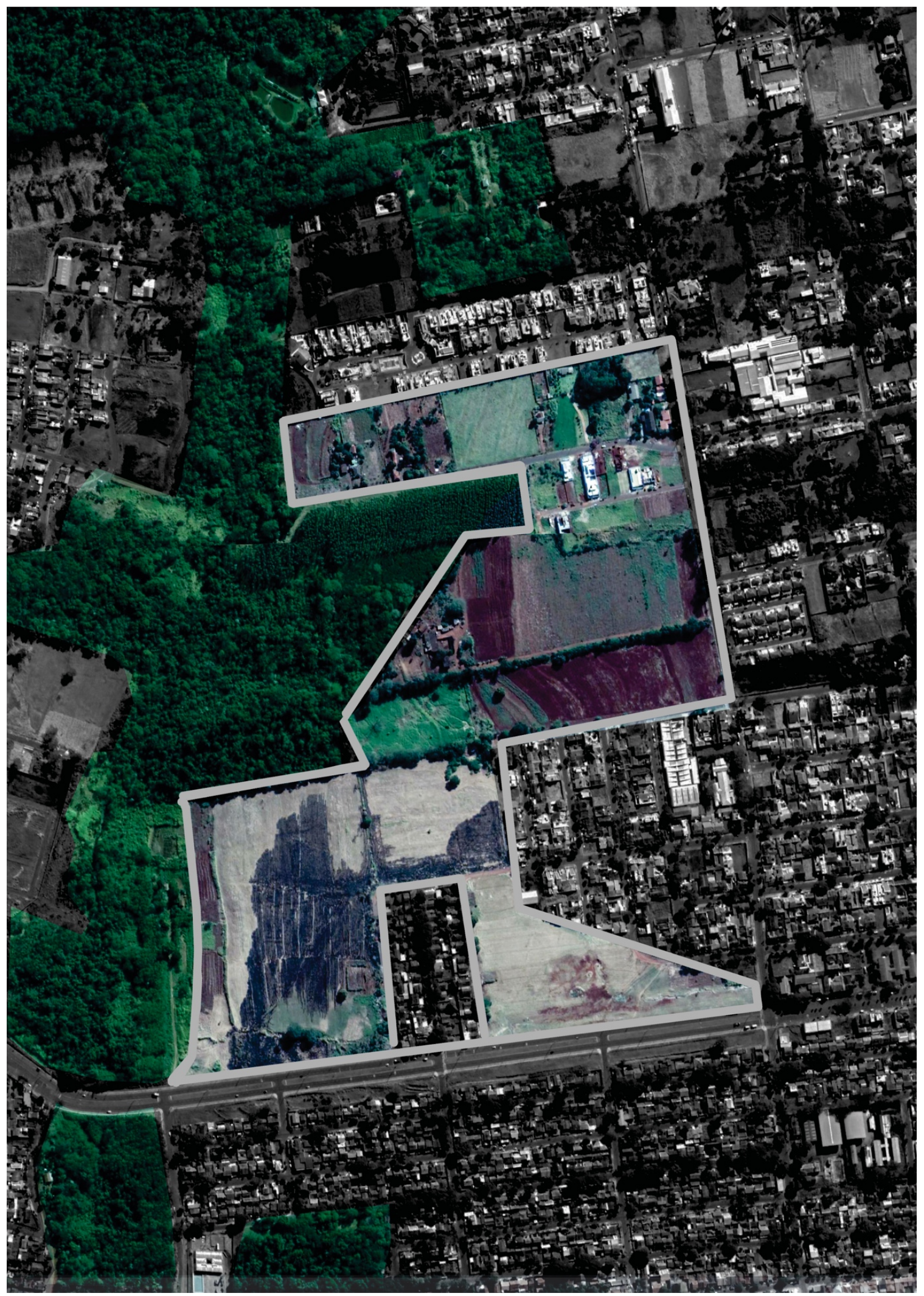

Figura 7 - Área de estudo Oficina PNUM 2018. Fonte: Acervo do grupo de pesquisa Cidade e Paisagem (UEM).

0 traçado das novas áreas urbanas teve que considerar o meio físico suporte, as condicionantes urbanas existentes, os preceitos da ecologia da paisagem e, sobretudo, as qualidades ambientais, estéticas e espaciais da forma urbana projetada. A tipologia predominante deveria ser reconhecida, assim como as 
características da unidade paisagem, e tratada como moldura morfológica. A cunha verde que permeava a área deveria ser considerada pelo seu papel ecológico e sistêmico, além de incorporada à proposta como opção de lazer urbano para o novo bairro.

A cidade de Maringá é comumente associada à vegetação urbana expressiva, especialmente aquela de acompanhamento viário, às calçadas largas e às vias hierarquizadas, e seu projeto original previa núcleos secundários no centro geométrico dos bairros residenciais, reunindo o comércio local entorno de uma praça. Essas características positivas da forma urbana maringaense não aparecem nos loteamentos mais recentes, acarretando perda de legibilidade, de identidade (ou individualidade) e de quantidade e qualidade dos espaços públicos livres. 0 urbanismo do traçado original da cidade, com base na ideia de que a cidade é uma obra de arte elaborada a partir da composição artística dos elementos da forma urbana, acabou sendo substituído por um urbanismo de traçados mais mecânicos e esquemáticos. Esse aspecto negativo da evolução urbana também deveria ser abordado no âmbito do projeto a ser realizado. Cabia aí uma postura crítica entre o existente e o desejável, sem, com isso, refutar drasticamente o modo de habitar sedimentado na vizinhança.

De acordo com Strappa (2019, p. 87), a ordem reconhecida nas formas existentes não é apenas aquela que se conseguiu lograr no passado, mas contém uma nova, futura possível ordem. Desse modo, a morfologia urbana é encarada como o estudo de sistemas abertos, em que a conformação reconhecida em um número finito de casos permite gerar um número infinito de possibilidades, das quais os arquitetos selecionam a mais apropriada. A noção de "mais apropriada" tem que considerar os processos formativos e a especificidade de cada área cultural, quer dizer, tem que corresponder à sequência de operações críticas que gradualmente reduz o número de possibilidades, levando a uma forma individualizada, única (Strappa, 2019, p. 87).

Após o referencial teórico fornecido pelas apresentações iniciais, os participantes realizaram visita à área de 30 hectares para reconhecer os tipos edilícios das áreas vizinhas ocupadas, a área de reserva florestal, o córrego e suas nascentes, e observar a rápida transformação da paisagem local. Depois, reunidos em pequenos grupos, finalizaram a análise morfológica, delinearam a ocupação da área-alvo, conectando a estrutura urbana existente e propondo um parque linear. Os esboços foram apresentados e avaliados por todo o grupo, e os conceitos iniciais foram verificados. Apesar dos resultados pouco aprimorados em função do tempo exíguo do exercício, o aspecto positivo da experiência residiu na aproximação teórica mais consistente da morfologia e no entendimento das suas possibilidades de aplicação. Entre os participantes - alunos de graduação e de pós-graduação, docentes, técnicos e profissionais liberais - havia aqueles que tiveram contato com esses conceitos pela primeira vez.

Outro ponto a se destacar é o método projetual adotado. Com o desenho das vias e das quadras, uma textura das unidades de paisagem adjacentes era também reproduzida nos novos lotes, sugerindo a materialização da futura ocupação dessas parcelas imitando a tipologia da moldura morfológica. Imagens de satélite obtidas com o Google Earth serviram de referência gráfica. Assim, foi possível obter propostas com texturas semelhantes ou diferentes às do entorno, e, dessa maneira, a percepção do produto tornou-se mais palpável durante o processo de elaboração do projeto.

A aproximação da morfologia urbana como método de leitura e compreensão dos processos de desenvolvimento da cidade, integrada a preceitos da ecologia da paisagem, foi extremamente bem-vista pelos participantes da oficina como forma de planejamento e projeto ambiental e socialmente sustentável.

\section{Referências}

Beloto, G. E., \& Coimbra, M. H. (2019). Modelo de expansão urbana e repercussão de novas centralidades. In Actas da 7ª Conferência da Rede Lusófona de Morfologia Urbana (pp. 1084-1100). Porto: Universidade do Porto.

Recuperado em 17 de setembro de 2019, de https://pnum.arq.up.pt 
Braga, S. S., \& Rego, R. L. (2019). Ideias de núcleos comerciais e a forma urbana. In Actas da 7a Conferência da Rede Lusófona de Morfologia Urbana (pp. 1101-1112). Porto: Universidade do Porto. Recuperado em 17 de setembro de 2019, de https://pnum.arq.up.pt

Castex, J., \& Panerai, P. (1970). Notes sur la structure de l'espace urbain. L'Architecture d'Aujourd'Hui, 153, 30-33.

Conzen, M. R. G. (1969). Alnwick, Northumberland: a study in town-plan analysis. London: Institute of British Geographers.

Conzen, M. R. G. (2004). Thinking about urban form: papers on urban morphology, 1932-1998. Oxford: Peter Lang.

Costa, S. A. P., \& Netto, M. M. G. (2015). Fundamentos de morfologia urbana. Belo Horizonte: C/Arte.

Costa, S. A. P., \& Teixeira, M. C. V. (2014). The study of urban form in Brazil. Urban Morphology, 18(2), 119-127.

Gauthier, P. (2005). Conceptualizing the social construction of urban and architectural forms through the typological process. Urban Morphology, 9(2), 83-93.

Hopkins, M. I. W. (2003). Using fringe belts to examine the relationships between urban morphology and urban ecology (PhD thesis). The University of Birmingham, Birmingham.

International Seminar on Urban Form - ISUF. (2019). Recuperado em 17 de setembro de 2019, de http://www.urbanform.org/glossary.html

Kropf, K. (2011). Urbanism, politics and language: the role of urban morphology. Urban Morphology, 15(2), 157 161.

Macedo, S. S., Queiroga, E. F., Campos, A. C. M. A., \& Custódio, V. (Eds.). (2018). Quadro geral da forma e do sistema de espaços livres das cidades brasileiras. São Paulo: FAUUSP.

Meneguetti, K. S. (2015). Faixas de hiato urbano em cidades novas planejadas: Maringá, Paraná. In X Colóquio QUAPÁ-SEL: produção e apropriação dos espaços livres e da forma urbana. Brasília: Universidade de Brasília.

Meneguetti, K. S., \& Costa, S. A. P. (2015). The fringe-belt concept and planned new towns: a Brazilian case study. Urban Morphology, 19(1), 25-33.

Meneguetti, K. S., Beloto, G. E., \& Rego, R. L. (2017). 0 tipo como produto cultural em uma área de conurbação recente. In Anais da 6 ${ }^{a}$ Conferência da Rede Lusófona de Morfologia Urbana (pp. 67-74). Vitória: Universidade Federal do Espírito Santo.

Meneguetti, K. S., Rego, R. L., \& Beloto, G. E. (2012). Espaços livres e paisagem na mancha urbana de Maringá - PR. In A. C. A. Campos, E. F. Queiroga, F. C. Galender, H. N. Degreas, R. Akamine, S. S. Macedo, V. Custodio (Eds.), Quadro dos sistemas de espaços livres nas cidades brasileiras (pp. 103-116). São Paulo: FAUUSP.

Oliveira, F. L. (2017). Green Wedge Urbanism: history, theory and contemporary practice. Londres: Bloomsbury. http://dx.doi.org/10.5040/9781474229227.

Oliveira, V. (2016a). Urban morphology: an introduction to the study of the physical form of cities. Dordrecth: Springer. http://dx.doi.org/10.1007/978-3-319-32083-0.

Oliveira, V. (2016b). Morfologia urbana: diferentes abordagens. Revista de Morfologia Urbana, 4(2), 65-84.

Oliveira, V. (Ed.). (2018). Diferentes abordagens em morfologia urbana: contributos luso-brasileiros. Portugal: Urban Forms. Recuperado em 9 de julho de 2019, de https://vitoroliveira.fe.up.pt/pdf/diferentes-abordagens-emmorfologia-urbana.pdf

Oliveira, V., \& Monteiro, C. (Eds.). (2015). Diferentes abordagens no estudo da forma urbana. Porto: FEUP.

Panerai, P. (2006). Análise urbana. Brasília: Editora da Universidade de Brasília.

Pereira, J. A., Meneguetti, K. S., \& Rego, R. L. (2011). Urban fringe belts em cidades novas: o caso de Maringá - PR. Paisagem \& Ambiente, 29(1), 85-102. http://dx.doi.org/10.11606/issn.2359-5361.v0i29p85-102. 
Rego, R. L. (2015). A integração cidade-campo como esquema de colonização e criação de cidades novas: do norte paranaense à Amazônia Legal. Revista Brasileira de Estudos Urbanos e Regionais, 17(1), 89-103.

http://dx.doi.org/10.22296/2317-1529.2015v17n1p89.

Rego, R. L. (2017a). Shaping an urban Amazonia: 'a planner's nightmare'. Planning Perspectives, 32(2), 249-270. http://dx.doi.org/10.1080/02665433.2016.1277952.

Rego, R. L. (2017b). Unidade de vizinhança: um estudo de caso das transformações de uma ideia urbanística. urbe. Revista Brasileira de Gestão Urbana, 9(3), 401-413. http://dx.doi.org/10.1590/2175-3369.009.003.ao01.

Rego, R. L., \& Meneguetti, K. S. (2008). British urban form in twentieth-century Brazil. Urban Morphology, 12(1), 25-34.

Rego, R. L., \& Meneguetti, K. S. (2010). Planted towns and territorial organization: the morphology of a settlement process in Brazil. Urban Morphology, 14(2), 101-109.

Rego, R. L., \& Meneguetti, K. S. (2011). A respeito de morfologia urbana: tópicos básicos para estudos da forma da cidade. Acta Scientiarum, 33(2), 123-127. http://dx.doi.org/10.4025/actascitechnol.v33i2.6196.

Strappa, G. (2019). Urban morphology and architectural design: a contemporary condition. Urban Morphology, 23(1), 86-87.

Universidade Estadual de Maringá - UEM. (2019). Maringá. Recuperado em 9 de julho de 2019, de https://pnum2019.wixsite.com/oficina

Whitehand, J. W. R. (2001). British urban morphology: the Conzenian tradition. Urban Morphology, 5(2), 103-109.

Whitehand, J. W. R. (2019). Green space in urban morphology: a historico-geographical approach. Urban Morphology, 23(1), 5-17.

Editores convidados: Vitor Oliveira (Universidade do Porto, Portugal) e Bruno Zaitter (PUCPR, Brasil)

Recebido: Set. 19, 2019

Aprovado: Nov. 25, 2019 


\section{Errata}

No artigo "Morfologia urbana como instrumento projetual", com o número de DOI https://doi.org/10.1590/2175-3369.012.e20190266, publicado na urbe. Revista Brasileira de Gestão Urbana, vol. 12, e20190266,

onde se lia:

Seção Temática: 0 Estudo da Forma Urbana no Brasil

leia-se:

Seção Temática: 0 Estudo da Forma Urbana no Brasil (Editores convidados: Vitor Oliveira e Bruno Zaitter)

onde se lia:

Editores: Bruno Zaitter e Vitor Oliveira

leia-se:

Editores convidados: Vitor Oliveira (Universidade do Porto, Portugal) e Bruno Zaitter (PUCPR, Brasil) 